\title{
Healthcare-associated Infections in Pediatric Patients in Neurotrauma Intensive Care Unit: A Retrospective Analysis
}

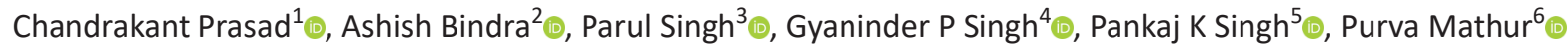

\begin{abstract}
Background: Healthcare-associated infections (HAls) can impact the outcome following traumatic brain injury (TBI) in children. We undertook a retrospective observational study to see the incidence, risk factors, and microbiological profile for HAls in pediatric TBI. We also studied the impact of baseline patient characteristics, HAls on patient outcome, and antibiotic resistance of different types of bacteria.

Materials and methods: Data on pediatric TBI patients of age up to 12 years were collected via a computerized patient record system (CPRS) from January 2012 to December 2018. Descriptive Chi-square test and Wilcoxon signed rank test were used to characterize baseline parameters. General linear regression models were run to find an unadjusted and adjusted odds ratio (OR).

Results: HAls were found in 144 (34\%) out of 423 patients. The most commonly seen infections were of the respiratory tract in 73 (17.26\%) subjects. The most predominant microorganism isolated was Acinetobacter baumannii in $188(41 \%)$ samples. A. baumannii was sensitive to colistin in 91 (48.4\%) patients. Male gender (OR 0.630; $p$-value 0.035), fall from height (OR 0.374; $p$-value 0.008 ), and higher injury severity scale (ISS) (OR 1.040; $p$-value 0.002) were independent risk factors for development of HAls. Severe TBI, higher ISS and Marshall grade, and HAls were significantly associated with poor patient outcome.

Conclusion: Severe TBI poses a significant risk of HAls. The most common site was the respiratory tract, predominately infected with $A$. baumannii. HAls in pediatric TBI patients resulted in poor patient outcome.

Keywords: Healthcare-associated infection, Pediatric, Trauma, Traumatic brain injury.

Indian Journal of Critical Care Medicine (2021): 10.5005/jp-journals-10071-24012
\end{abstract}

\section{HIGHLIGHTS}

Along with neurological morbidity, pediatric traumatic brain injury poses a significant risk of HAls. Higher injury severity score, male gender, and fall from height were associated with a significant risk of infections. Respiratory tract infections are the most common in these patients. Severe injuries with HAls resulted in poor outcome.

\section{INTRODUCTION}

Traumatic brain injury (TBI) is one of the leading causes of morbidity and mortality in children both in the developing and developed world. ${ }^{1}$ Along with neurological morbidity, neurotrauma poses a significant risk of infections. Improvement in outcome from TBI can be hampered by the development of healthcare-associated infections (HAIs). The reported incidence rate is as high as $50 \%$ and mortality as high as $37 \% .{ }^{2}$ Among critically ill, pediatric trauma patients are at the highest risk of the development of HAls. ${ }^{3}$ Transient immunosuppression or immunoparalysis associated with neurological insults secondary to cytokine release and brainstem irritation induced activation of the hypothalamus-pituitary-adrenocortical axis contribute to HAls in TBI. ${ }^{4}$ HAls can also lead to multiple organ dysfunction along with worsening secondary brain injury. ${ }^{5}$

Results of adequate effort to manage such critically ill children can be optimized by knowing epidemiological data and understanding of risk factors for the development of HAls. We, therefore, undertook a retrospective, observational study to see the $\mathrm{HAl}$ on rate in pediatric patients admitted to neurotrauma intensive care units over a period of 7 years.

We analyzed the microbiological samples of all the pediatric TBI patients with suspicion of HAls submitted for culture and

\footnotetext{
1,2,4 Department of Neuroanesthesiology and Critical Care, All India Institute of Medical Sciences, New Delhi, India

${ }^{3}$ Department of Microbiology, All India Institute of Medical Sciences, New Delhi, India

${ }^{5}$ Department of Neurosurgery, All India Institute of Medical Sciences, New Delhi, India

${ }^{6}$ Laboratory Medicine, Jai Prakash Narain Apex Trauma Center, All India Institute of Medical Sciences, New Delhi, India
}

Corresponding Author: Ashish Bindra, Department of Neuroanesthesiology and Critical Care, All India Institute of Medical Sciences, New Delhi, India, Phone: +91 8826417127, e-mail: dr_ ashi2208@yahoo.com

How to cite this article: Prasad C, Bindra A, Singh P, Singh GP, Singh PK, Mathur P. Healthcare-associated Infections in Pediatric Patients in Neurotrauma Intensive Care Unit: A Retrospective Analysis. Indian J Crit Care Med 2021;25(11):1308-1313.

Source of support: Nil

Conflict of interest: None

antimicrobial susceptibility testing. We also studied risk factors for HAls and the impact of baseline characteristics, HAI on outcome, and antibiotic resistance in different types of bacteria isolated in these patients.

\section{Materials and Methods}

After taking approval from the institutional ethics committee (IEC-887/04.09.2020), we did a retrospective analysis of pediatric

(-) The Author(s). 2021 Open Access This article is distributed under the terms of the Creative Commons Attribution 4.0 International License (https://creativecommons. org/licenses/by-nc/4.0/), which permits unrestricted use, distribution, and non-commercial reproduction in any medium, provided you give appropriate credit to the original author(s) and the source, provide a link to the Creative Commons license, and indicate if changes were made. The Creative Commons Public Domain Dedication waiver (http://creativecommons.org/publicdomain/zero/1.0/) applies to the data made available in this article, unless otherwise stated. 
trauma patients admitted at level 1 trauma center. We analyzed microbiological samples of pediatric TBI patients from January 2012 to December 2018, which were submitted to the microbiology laboratory for testing. All the positive culture isolates were identified up to the species level by the Vitek 2 GN card (version 8.1, Inc., Durham, United States of America). Antimicrobial susceptibility testing was performed by Kirby-Bauer disc diffusion method on Mueller Hinton agar and by Vitek 2 system. The results of antibiotic susceptibility were interpreted based on the Clinical and Laboratory Standards Institution guidelines.

Clinical characteristics and admission variables were collected via the computerized patient record system (CPRS) database. CPRS (version 1.0.26.76), supported by Edgeware Technologies India PVT limited, was used. Data of all the trauma patients were entered and updated in this system by all the concerned clinical and technical staff. We used predecided proforma to retrieve the data of patients who met inclusion and exclusion criteria. All the data were entered into an excel worksheet for final analysis.

Patients up to 12 years of age, of either gender, with TBI admitted to neurotrauma intensive care unit were included. Children who were brought dead or had signs of infection at the time of admission or up to 48 hours after admission were excluded from the study. Patients with a length of hospital stay less than 48 hours were excluded. We retrieved data of culture and sensitivity results along with details of corresponding samples. Data of 423 patients were included for analysis after screening for inclusion and exclusion criteria. Data collected included patient demographics (age, gender), admission Glasgow coma score (GCS), mechanism of injury, computed tomography (CT) findings at admission, Marshall grading, injury severity score, details of invasive devices, microbiological infections, antimicrobial sensitivity, the outcome in terms of length of hospital stay, GCS at discharge, and mortality.

Patients were classified into two groups: group A (with HAls) and group B (without HAls). For descriptive purposes, microorganisms were divided into Gram-negative bacilli (GNB), Gram-positive cocci (GPC), and fungi. For all analysis purposes, patients were further subclassified into age-groups 0-2 years, 2-4 years, and 4-12 years. TBI was divided into mild, moderate, and severe head injuries based on admission GCS (13-15 mild, 9-12 moderate, and 3-8 severe). The injury type was described as either polytrauma or isolated TBI. Mechanism of injury was categorized into fall from a height, road traffic accident (RTA), penetrating injuries, and others (suffocation, drowning, and poisoning). Marshall grading was done based on findings of admission CT scan. ${ }^{6}$ The injury severity scale (ISS) calculation was based on the highest abbreviated injury scale (AIS) code of the three most injured body regions. ${ }^{7}$ All the different types of samples like respiratory samples [broncho-alveolar lavage (BAL), tracheal aspirate, endotracheal tubes], blood, urine, cerebrospinal fluid (CSF), bone/tissue, and invasive devices were analyzed. Invasive devices included intracranial pressure (ICP) monitoring catheters, external ventricular drains (EVD), and intercostal drains (ICD). The outcome was calculated based on the length of hospital stay and neurological status at discharge. Latter was classified into mild, moderate, and severe categories based on GCS at discharge along with class 4 given to dead patients. Duration of hospital stay was calculated in days.

\section{Statistical Methods}

Descriptive statistical methods were used to analyze intragroup characteristics. Intergroup baseline characteristics were compared using Chi-square tests for categorical variables and Wilcoxon signed rank test for continuous nonparametric variables. Incidence of all infections and antibiotic sensitivity were calculated using descriptive analysis cross-tab model. The unadjusted and adjusted odds ratios (OR) of risk factors for different HAls and mortality were derived using univariate and multiple logistic regression analyses, respectively. Models were run first without adjustment for confounding variables to find potential risk factors. The final multiple regression model was run based on the level of significance $(p$-value $<0.05)$ seen in the unadjusted logistic regression model to find confounder adjusted risk factors for infections and mortality. The impact of infections and binary baseline characteristics on the outcome (hospital stay and discharge status) was analyzed using the Mann-Whitney U test. Spearman's rho and Pearson's correlation coefficient were derived to find out the relation between categorical and continuous baseline characteristics of patient outcome, respectively. Chi-square tests were run to find the association between mortality and all categorical variables. Statistical analysis was performed using the SPSS for Windows 25 (SPSS, Chicago, Illinois, United States). A p-value of less than 0.05 was considered statistically significant.

\section{Results}

Microbiological samples for 423 pediatric TBI patients were analyzed. Demographic data and baseline characteristics of patients are described in Table 1. A total of $232(54.8 \%)$ children had severe TBI. The majority of the patients, 395 (93.4\%), had isolated TBI. The most common mechanism of injury was fall from height in $274(64.8 \%)$ patients. The baseline variables were comparable across the groups except for gender, mechanism of injury, and ISS. Group A patients had significantly higher ISS value ( $p$-value 0.003 ) as shown in Table 1.

A total of 2,781 samples of 423 patients were received for culture, out of which 454 (16.3\%) samples turned positive in 144 (34\%) patients. Maximum infections were found in respiratory samples, 73 (17.3\%) patients followed by blood in 45 (10.6\%). Next in sequence were wound 39 (9.2\%), CSF 21 (4.9\%), urine 18 (4.3\%), bone/tissue 12 (2.8\%), and invasive device 4 (0.9\%) (Table 2). GNB grown in cultures of 351 (12.6\%) isolates while GPC in 103 (3.2\%) (Supplementary Table 1).

Acinetobacter baumannii was the most commonly isolated [188 (41\%)] microorganisms in blood, respiratory tract, 92 (60\%); CSF, 45 (52\%); and invasive device, 5 (31\%). Staphylococcus aureus was the most common microorganism isolated in wound 39 (45.4\%) and bone/tissues 3 (75\%). Escherichia coli grew commonly in urine 9 (30\%) (Supplementary Table 2).

GNB and GPC bacteria were classified separately as per their sensitivity to antibiotics. A. baumannii was found to be sensitive to colistin in 91 (48.4\%) cases followed by tigecycline in 65 (34.5\%) and netilmicin in 26 (13.83\%). It was resistant to all remaining antibiotics. S. aureus was sensitive to linezolid in 74 (91.4\%), teicoplanin in $73(90.1 \%)$, and vancomycin in $73(90.1 \%)$. Colistin in 30 (78.9\%), tigecycline in 24 (63.2\%), amikacin in 22 (57.9\%), and meropenem in $19(50 \%)$ were found effective against E. coli (Supplementary Tables 3 and 4).

Potential and independent risk factors for HAls were derived using univariate and multiple logistic regression analysis, respectively. Sample-wise specific risk factors for different HAls were also listed (Table 3). Male gender, fall from height, and higher ISS were found as potential as well as independent risk factors for HAls (OR 0.630; $p$-value 0.035,OR 0.374; $p$-value 0.008, and OR 1.040; 
Table 1: Demographic profile and baseline characteristics of patients

\begin{tabular}{|c|c|c|c|c|}
\hline \multirow[b]{2}{*}{ Variable } & \multirow[b]{2}{*}{ Intragroup $(N=423)$} & \multicolumn{3}{|c|}{ Intergroup } \\
\hline & & $\begin{array}{c}\text { Group A } \\
(N=144)\end{array}$ & $\begin{array}{c}\text { Group B } \\
(N=279)\end{array}$ & $p$ value \\
\hline Age (mean, SD) & $5.44(3.41)$ & $5.63(3.31)$ & $5.33(3.46)$ & 0.269 \\
\hline \multicolumn{5}{|l|}{ Age distribution ( $n, \%)$} \\
\hline $0-2$ years & $106(25.1)$ & $34(23.6)$ & $72(25.8)$ & 0.307 \\
\hline $2-4$ years & $97(22.9)$ & $28(19.4)$ & $69(24.7)$ & \\
\hline $4-12$ years & $220(52.0)$ & $82(56.9)$ & $138(49.5)$ & \\
\hline Sex $(M: F)$ & 279:144 & $85: 59$ & $194: 85$ & 0.031 \\
\hline Admission GCS (median, IQR) & $7(3-15)$ & $7(3-15)$ & $8(3-15)$ & 0.181 \\
\hline \multicolumn{5}{|l|}{ Admission status $(n, \%)$} \\
\hline Mild (GCS 13-15) & $123(29.1)$ & $40(27.8)$ & $83(29.7)$ & 0.532 \\
\hline Moderate (GCS 9-12) & $68(16.1)$ & $20(13.9)$ & $48(17.2)$ & \\
\hline Severe (GCS 3-8) & $232(54.8)$ & $84(58.3)$ & $148(53.0)$ & \\
\hline \multicolumn{5}{|l|}{ Type of injury $(n, \%)$} \\
\hline Polytrauma & $28(6.6)$ & $12(8.3)$ & $16(5.7)$ & 0.308 \\
\hline Isolated TBI & $395(93.4)$ & $132(91.7)$ & $263(94.3)$ & \\
\hline \multicolumn{5}{|l|}{ Mechanism of injury $(n, \%)$} \\
\hline Fall from height & $274(64.8)$ & $80(55.6)$ & $194(69.5)$ & 0.032 \\
\hline Road traffic accident & $104(24.6)$ & $44(30.6)$ & $60(21.5)$ & \\
\hline Penetrating injury & $9(2.1)$ & $3(2.1)$ & $6(2.2)$ & \\
\hline Others & $36(8.5)$ & $17(11.8)$ & $19(6.8)$ & \\
\hline \multicolumn{5}{|l|}{ Marshall grade $(n, \%)$} \\
\hline Grade 1 & $78(11.3)$ & $17(11.8)$ & $31(11.1)$ & \\
\hline Grade 2 & $270(63.8)$ & $85(59.0)$ & $185(66.3)$ & 0.565 \\
\hline Grade 3 & $22(5.2)$ & $11(7.6)$ & $11(3.9)$ & \\
\hline Grade 4 & $15(3.5)$ & $5(3.5)$ & $10(3.60)$ & \\
\hline Grade 5 & $65(15.4)$ & $25(17.4)$ & $40(14.3)$ & \\
\hline Grade 6 & $3(0.7)$ & $2(0.7)$ & $1(0.7)$ & \\
\hline Injury severity scale (mean, SD) & $11(8.29)$ & $12.70(8.20)$ & $10.13(8.16)$ & 0.003 \\
\hline Invasive devices (ICP sensor, EVD, ICD) ( $n, \%)$ & $90(21.3)$ & $36(25.0)$ & $54(19.4)$ & 0.179 \\
\hline
\end{tabular}

GCS, Glasgow Coma Scale; ICP, intracranial pressure; EVD, external ventricular drain; ICD, intercostal drain

Table 2: Incidence of infections in studied patient population

\begin{tabular}{lcc}
\hline & Number of patients & Percentage \\
\hline Any healthcare-associated infection & 144 & 34.04 \\
Blood infections & 45 & 10.64 \\
Wound infections & 39 & 9.22 \\
Respiratory infections & 73 & 17.26 \\
CSF infections & 21 & 4.96 \\
Urine infections & 18 & 4.26 \\
Invasive device infections & 12 & 2.84 \\
Bone/tissue infections & 4 & 0.95 \\
\hline
\end{tabular}

CSF, cerebrospinal fluid

$p$-value 0.002 , respectively) Severe TBI (OR 0.371; $p$-value 0.018 ) and higher ISS (OR 1.061; $p$-value $<0.001$ ) turned as independent predictors for respiratory tract infection while male gender was found as risk factor (OR 0.216 ; $p$-value 0.004 ) for urinary tract infections. Confounder adjusted risk factors for CSF infection were higher ISS (OR 0.937; $p$-value 0.019). Severe TBI (OR 2.416; $p$-value 0.022 ) and fall from height (OR 0.248; $p$-value 0.003 ) came out as independent risk factors for wound infections while lower agegroup ( $0-2$ years) was a risk factor for device-related infections (OR 9.140; $p$-value 0.004).

The outcome was analyzed in terms of length of hospital stay 12 $(2-1,289)$ days, discharge GCS 13 (3-15), and mortality in 29 (6.9\%) patients (Table 4). Severe TBI and higher ISS ( $p$-value $<0.001$ for both) significantly prolonged hospital stay, while the same factors along with advanced Marshall grade were found as significant predictors for poor GCS at discharge ( $p$-value $<0.001$ for all) and mortality ( $p$-value $0.020,<0.001$ and $<0.001$, respectively).

HAls were found to prolong the hospital stay ( $p$-value $<0.001$ ) and predict poor GCS at discharge ( $p$-value 0.003) (Table 5). Among HAls, blood infections ( $p$-value 0.021), respiratory infections ( $p$-value $<0.001)$, urinary infections ( $p$-value 0.001), and device-related infections ( $p$-value 0.032 ) were found to significantly increase the duration of hospital stay. Poor discharge GCS was associated with respiratory infections ( $p$-value $<0.001)$ and device-related infections ( $p$-value 0.001). CSF infections ( $p$-value 0.013 ) were found to be significantly associated with patient mortality (Supplementary Table 5).

\section{Discussion}

Along with other ailments, neurotrauma is a constant threat to the health of children both in the developed and developing world. HAls in pediatric TBI patients pose a special challenge while managing pediatric TBI patients. Such infections can have a significant impact on the length of hospital stay, patient outcome, and healthcare costs. ${ }^{8}$ Infection rate, microorganisms type, and antimicrobial susceptibility pattern may vary across the globe. Keeping these facts in mind, we planned this retrospective study 
HAIs in TBI Children

Table 3: Risk factors for HAls overall and specific for different infection sites

\begin{tabular}{|c|c|c|c|c|}
\hline \multirow[b]{2}{*}{ Variable } & \multicolumn{2}{|c|}{ Odds of infection } & \multicolumn{2}{|c|}{ Adjusted odds of infection } \\
\hline & OR & $p$ value & OR (lower $\mathrm{Cl}$, upper $\mathrm{Cl}$ ) & $p$ value \\
\hline \multicolumn{5}{|l|}{ Age distribution } \\
\hline $0-2$ years & 0.795 & 0.359 & & \\
\hline $2-4$ years & 0.683 & 0.148 & & \\
\hline Male sex & 0.631 & 0.031 & $0.630(0.410,0.967)$ & 0.035 \\
\hline \multicolumn{5}{|l|}{ Admission GCS } \\
\hline Mild & 0.849 & 0.488 & & \\
\hline Moderate & 0.734 & 0.302 & & \\
\hline Polytrauma & 1.494 & 0.311 & & \\
\hline \multicolumn{5}{|l|}{ Mechanism of injury } \\
\hline Fall from height & 0.461 & 0.031 & $0.374(0.171,0.774)$ & 0.008 \\
\hline Road traffic accident & 0.820 & 0.609 & & \\
\hline Penetrating injury & 0.559 & 0.457 & & \\
\hline Marshal Grading & 1.077 & 0.359 & & \\
\hline Injury severity scale & 1.037 & 0.003 & $1.040(1.015,1.066)$ & 0.002 \\
\hline Any invasive device & 0.720 & 0.180 & & \\
\hline Blood & \multicolumn{4}{|c|}{ No significant risk factor found } \\
\hline \multicolumn{5}{|l|}{ Respiratory tract } \\
\hline Male sex & 0.603 & 0.054 & $0.640(0.375,1.094)$ & 0.103 \\
\hline Severe head injury & 0.229 & $<0.001$ & $0.371(0.163,0.844)$ & 0.018 \\
\hline Injury severity scale & 1.075 & $<0.001$ & $1.061(1.028,1.095)$ & $<0.001$ \\
\hline \multicolumn{5}{|l|}{ Urine } \\
\hline Male sex & 0.242 & 0.005 & $0.216(0.076,0.612)$ & 0.004 \\
\hline \multicolumn{5}{|l|}{ CSF } \\
\hline Injury severity scale & 1.056 & 0.019 & $0.937(0.888,989)$ & 0.019 \\
\hline \multicolumn{5}{|l|}{ Wound } \\
\hline Severe head injury & 3.392 & 0.001 & $2.416(1.134,5.151)$ & 0.022 \\
\hline Fall from height & 0.183 & $<0.001$ & $0.248(0.100,0.616)$ & 0.003 \\
\hline Road traffic accident & 0.246 & 0.006 & $0.436(0.150,1.266)$ & 0.127 \\
\hline Any invasive device & 5.500 & 0.021 & $4.005(9.12,17.589)$ & 0.066 \\
\hline \multicolumn{5}{|l|}{ Device } \\
\hline $0-2$ years age group & 5.905 & 0.010 & $9.140(2.043,40.898)$ & 0.004 \\
\hline Bone/tissue & \multicolumn{4}{|c|}{ No significant risk factor found } \\
\hline
\end{tabular}

Table 4: Impact of baseline characteristics on outcome

\begin{tabular}{|c|c|c|c|c|c|c|}
\hline \multirow[b]{2}{*}{ Variable } & \multicolumn{2}{|c|}{ Prolonged hospital stay } & \multicolumn{2}{|c|}{ Poor discharge status (GCS) } & \multicolumn{2}{|c|}{ Mortality } \\
\hline & Mean rank & $p$ value & Mean rank & pvalue & Chi-square value & pvalue \\
\hline Type of Injury & & 0.347 & & 0.008 & 2.207 & \\
\hline Polytrauma & 191.00 & & 159.13 & & $(n=0)$ & 0.137 \\
\hline \multirow[t]{2}{*}{ Isolated TBI } & 213.49 & & 215.75 & & $(n=29)$ & \\
\hline & rvalue & $p$ value & rvalue & $p$ value & Chi-square value & $p$ value \\
\hline Admission GCS & 0.306 & $<0.001$ & 0.449 & $<0.001$ & 7.802 & 0.020 \\
\hline Mechanism of injury & 0.036 & 0.459 & 0.049 & 0.319 & 3.707 & 0.295 \\
\hline Marshall grading & 0.089 & 0.068 & 0.180 & $<0.001$ & 24.773 & $<0.001$ \\
\hline Injury severity scale & 0.191 & $<0.001$ & 0.701 & $<0.001$ & 85.10 & $<0.001$ \\
\hline
\end{tabular}

GCS, Glasgow Coma Scale; TBI, traumatic brain injury

to see HAls profile and associated risk factors to address challenges during care and prognostication of pediatric TBI patients.

We found a $34 \%$ incidence of HAls in pediatric TBI patients admitted to neurotrauma intensive care units. Data from West report a $13.3-50 \%$ incidence of HAls in pediatric polytrauma patients. ${ }^{2,9} \mathrm{~A}$ study by Osborn and colleagues reports a $2 \%$ incidence of sepsis among 30,303 trauma patients across all age-groups. ${ }^{10}$ Sbrinick et al. reported a $13 \%$ incidence of infection in pediatric polytrauma with TBI. ${ }^{9}$ However, we found higher incidence HAls in predominately TBI patients. The incidence of infection is more in trauma care units as compared to other critically ill patients. We witnessed a high incidence of respiratory tract infections (17\%), which is higher as 
Table 5: Comparison of effect of HAls on outcome in both the groups

\begin{tabular}{|c|c|c|c|c|c|c|c|c|}
\hline \multirow[b]{2}{*}{ Infection sites } & \multicolumn{3}{|c|}{ Prolonged hospital stay } & \multicolumn{3}{|c|}{ Poor discharge status } & \multicolumn{2}{|c|}{ Mortality } \\
\hline & $\begin{array}{c}\text { Group A } \\
\text { (mean rank) }\end{array}$ & $\begin{array}{c}\text { Group B } \\
\text { (mean rank) }\end{array}$ & $p$ value & $\begin{array}{c}\text { Group A } \\
\text { (mean rank) }\end{array}$ & $\begin{array}{c}\text { Group B } \\
\text { (mean rank) }\end{array}$ & $p$ value & $\begin{array}{c}\text { Chi-square } \\
\text { value }\end{array}$ & $p$ value \\
\hline Any infection & 248.50 & 193.16 & $<0.001$ & 234.40 & 200.44 & 0.003 & 0.746 & 0.388 \\
\hline Blood & 251.72 & 207.27 & 0.021 & 231.08 & 209.73 & 0.216 & 0.326 & 0.568 \\
\hline Respiratory & 261.16 & 201.75 & $<0.001$ & 263.35 & 201.29 & $<0.001$ & 1.032 & 0.310 \\
\hline Urine & 304.64 & 207.88 & 0.001 & 244.44 & 210.56 & 0.199 & 0.050 & 0.823 \\
\hline CSF & 239.55 & 210.56 & 0.289 & 254.02 & 209.80 & 0.071 & 9.946 & 0.002 \\
\hline Wound & 229.44 & 210.23 & 0.350 & 196.35 & 213.59 & 0.349 & 4.894 & 0.027 \\
\hline Device & 286.50 & 209.32 & 0.032 & 295.25 & 209.57 & 0.001 & 1.872 & 0.172 \\
\hline Bone/tissue & 180.63 & 212.30 & 0.606 & 190.00 & 212.21 & 0.701 & 2.082 & 0.149 \\
\hline
\end{tabular}

GCS, Glasgow Coma Scale

compared to data reported from Western countries. ${ }^{11}$ The incidence of bloodstream infections varies across different pediatric intensive care units around the globe. Incidence of bloodstream infection was reported up to $30 \%$ in the pediatric intensive care unit in north India earlier; however, an incidence as low as $0.06 \%$ has been reported in critically ill pediatric patients without trauma. ${ }^{12,13}$ Our data suggest around $11 \%$ incidence of bloodstream infections in pediatric TBI patients. Urinary tract and invasive device-related infections were less as compared to available data from Western countries. ${ }^{14,15}$

A. baumannii was the most common (41\%) overall isolate in our study. Klebsiella pneumoniae (24\%) and S. aureus (18\%) were isolated earlier as the most common microorganisms in blood in other pediatric intensive care units from developing countries; ${ }^{12}$ however, we found A. baumannii (21\%) and K. pneumoniae (19\%) to be more prevalent in pediatric TBI patients. S. aureus in our study were reported in only $6 \%$ of blood infections. A. baumannii was also the most common colonizer in the respiratory tract, CSF, and invasive device, which was in contrast to that reported from Western countries where $S$. aureus is the most common pathogen. ${ }^{14-16}$

A. baumannii was also found to be multidrug resistant in more than half of the patient population. It was found susceptible to colistin in $48.4 \%$ and tigecycline in $34.5 \%$ of patients. So, the largest portion of difficult-to-treat microbiota is shared by $A$. baumannii in our setup. Up to $77 \%$ susceptibility of $A$. baumannii was reported in a study in Kenya. ${ }^{17}$ Carbapenem resistance has been reported in $4.25-16 \%$ of $K$. pneumoniae to carbapenem in recent years. ${ }^{18}$ Our findings also suggest an alarming $40-50 \%$ carbapenem resistance for K. pneumoniae. The sensitivity pattern of S. aureus was derived as linezolid (91\%), teicoplanin (90\%), and vancomycin (90\%), similar to that described in Western countries as linezolid (97\%), teicoplanin (97\%), and vancomycin (95\%). ${ }^{19}$

In our study, male gender, fall from height, and higher ISS at admission were derived as independent risk factors for HAls. The predictive ability of ISS for HAls was supported by findings of Sribnick et al. ${ }^{9}$ Severe TBI and higher ISS are defined as risk factors for respiratory tract infections. ${ }^{11}$ Male gender was found to be a risk factor for urinary tract infections in our study contrary to the findings described earlier. ${ }^{20}$ Few studies also reported a significantly higher incidence of urinary tract infections in uncircumcised male children (20.1\%) than in circumcised ones (2.4\%). However, retrospectively we could not look into that aspect. Higher ISS was found as an independent predictive factor for CSF infection in pediatric TBI patients. ${ }^{14}$ Younger age-group ( $0-2$ years) was found more vulnerable for invasive device-related infection, probably owing to immunosuppression after TBI. ${ }^{4}$

In our study, severe TBI, higher ISS and Marshall grade were significantly associated with poor outcomes as reported in the literature. $^{21,22}$ Also, the HAls were found to be associated with an increased hospital stay, poor discharge GCS, and increased mortality. HAls result in increased intensive care unit and hospital stay and more discharge to the rehabilitation center., ${ }^{9,14}$

Our study represents HAls and their impact on the outcome in pediatric TBI patients, which is not widely reported. Though, our study is a single-center retrospective study that can be considered as limitations of this analysis; however, this could be mitigated to some extent due to large sample (>400) and long duration data (7 years) of one of the largest level 1 trauma care hospital in the country.

\section{Conclusion}

Pediatric TBI patients are prone to develop HAls. Multidrugresistant $A$. baumannii was the most common microorganism isolated in nosocomial pediatric TBI patients in our study. Male gender, severe TBI, and higher ISS were the main risk factors identified for HAls. Severe TBI, HAIs, higher ISS, and Marshall grade were found to be significantly associated with poor outcome in the present study. ${ }^{23}$

\section{OrCID}

Chandrakant Prasad (1) https://orcid.org/0000-0002-9848-1337

Ashish Bindra 이 https://orcid.org/0000-0001-5685-2833

Parul Singh $\odot$ https://orcid.org/0000-0002-3733-6283

Gyaninder P Singh @ https://orcid.org/0000-0002-6702-6892

Pankaj K Singh (1) https://orcid.org/0000-0001-8590-4786

Purva Mathur $\odot$ https://orcid.org/0000-0003-4429-3688

\section{References}

1. Shekhar C, Gupta LN, Premsagar IC, Sinha M, Kishore J. An epidemiological study of traumatic brain injury cases in a trauma centre of New Delhi (India). J Emerg Trauma Shock 2015;8(3):131139. DOI: 10.4103/0974-2700.160700. PMID: 26229295; PMCID: PMC4520025.

2. Araki T, Yokota H, Morita A. Pediatric Traumatic brain injury: characteristic features, diagnosis, and management. Neurol Med Chir (Tokyo) 2017;57(2):82-93. DOI: 10.2176/nmc.ra.2016-0191. 
3. Cardozo Júnior LC, Silva RR. Sepsis in intensive care unit patients with traumatic brain injury: factors associated with higher mortality. Rev Bras Ter Intensiva 2014;26(2):148-154. DOI: 10.5935/0103-507x.20140022.

4. Cutler GJ, Kharbanda AB, Nowak J, Ortega HW. Injury region and risk of hospital-acquired pneumonia among pediatric trauma patients. Hosp Pediatr 2017;7(3):164-170. DOI: 10.1542/hpeds.2016-0072.

5. Boddie DE, Currie DG, Eremin O, Heys SD. Immune suppression and isolated severe head injury: a significant clinical problem. $\mathrm{Br} J$ Neurosurg 2003;17(5):405-417. DOI: 10.1080/02688690310001611198.

6. Bronchard R, Albaladejo P, Brezac G, Geffroy A, Seince PF, Morris W, et al. Early onset pneumonia: risk factors and consequences in head trauma patients. Anesthesiology 2004;100(2):234-239. DOI: 10.1097/00000542-200402000-00009.

7. Mahadewa TGB, Golden N, Saputra A, Ryalino C. Modified Revised Trauma-Marshall score as a proposed tool in predicting the outcome of moderate and severe traumatic brain injury. Open Access Emerg Med 2018;8(10):135-139. DOI: 10.2147/OAEM.S179090.

8. Lecky F, Woodford M, Edwards A, Bouamra O, Coats T. Trauma scoring systems and databases. Br J Anaesth 2014;113(2):286-294. DOI: 10.1093/bja/aeu242.

9. Elward AM, Hollenbeak CS, Warren DK, Fraser VJ. Attributable cost of nosocomial primary bloodstream infection in pediatric intensive care unit patients. Pediatrics 2005;115(4):868-872. DOI: 10.1542/ peds.2004-0256.

10. Sribnick EA, Hensley J, Moore-Clingenpeel M, Muszynski JA, Thakkar RK, Hall MW. Nosocomial infection following severe traumatic injury in children. Pediatr Crit Care Med 2020;21(5):443-450. DOI: 10.1097/ PCC.0000000000002238.

11. Osborn TM, Tracy JK, Dunne JR, Pasquale M, Napolitano LM. Epidemiology of sepsis in patients with traumatic injury. Crit Care Med 2004;32(11):2234-2240. DOI: 10.1097/01.ccm.0000145586.23276.

12. Ortega HW, Cutler G, Dreyfus J, Flood A, Kharbanda A. Hospitalacquired pneumonia among pediatric trauma patients treated at national trauma centers. J Trauma Acute Care Surg 2015;78(6):11491154. DOI: 10.1097/TA.0000000000000661.

13. Lakshmi KS, Jayashree M, Singhi S, Ray P. Study of nosocomial primary bloodstream infections in a pediatric intensive care unit. J Trop Pediatr 2007;53(2):87-92. DOI: 10.1093/tropej/fml073.

14. Green N, Johnson AP, Henderson KL, Muller-Pebody B, Thelwall S, Robotham JV, et al. Quantifying the burden of hospital-acquired bloodstream infection in children in England by estimating excess length of hospital stay and mortality using a multistate analysis of linked, routinely collected data. J Pediatric Infect Dis Soc 2015;4(4):305-312. DOI: 10.1093/jpids/piu073.

15. Alharfi IM, Charyk Stewart T, Al Helali I, Daoud H, Fraser DD. Infection rates, fevers, and associated factors in pediatric severe traumatic brain injury. J Neurotrauma 2014;31(5):452-458. DOI: 10.1089/ neu.2013.2904.

16. Ngo QN, Ranger A, Singh RN, Kornecki A, Seabrook JA, Fraser DD. External ventricular drains in pediatric patients. Pediatr Crit Care Med 2009;10(3):346-351. DOI: 10.1097/PCC.0b013e3181a320cd.

17. Hamele M, Stockmann C, Cirulis M, Riva-Cambrin J, Metzger R, Bennett TD, et al. Ventilator-associated pneumonia in pediatric traumatic brain injury. J Neurotrauma 2016;33(9):832-839. DOI: 10.1089/neu.2015.4004.

18. Musyoki VM, Masika MM, Mutai W, Wilfred G, Kuria A, Muthini F. Antimicrobial susceptibility pattern of Acinetobacter isolates from patients in Kenyatta National Hospital, Nairobi, Kenya. Pan Afr Med J 2019;26(33):146. DOI: 10.11604/pamj.2019.33.146.17220.

19. Wang C, Yuan Z, Huang W, Yan L, Tang J, Liu CW. Epidemiologic analysis and control strategy of Klebsiella pneumoniae infection in intensive care units in a teaching hospital of People's Republic of China. Infect Drug Resist 2019;12(12):391-398. DOI: 10.2147/IDR. S189154.

20. Gitau W, Masika M, Musyoki M, Museve B, Mutwiri T. Antimicrobial susceptibility pattern of Staphylococcus aureus isolates from clinical specimens at Kenyatta National Hospital. BMC Res Notes 2018;11(1):226. DOI: 10.1186/s13104-018-3337-2.

21. Gondim R, Azevedo R, Braga AANM, Veiga ML, Barroso U Jr. Risk factors for urinary tract infection in children with urinary urgency. Int Braz J Urol 2018;44(2):378-383. DOI: 10.1590/S1677-5538. IBJU.2017.0434.

22. Bedry T, Tadele H. Pattern and outcome of pediatric traumatic brain injury at Hawassa University comprehensive specialized hospital, Southern Ethiopia: observational cross-sectional study. Emerg Med Int 2020;2020:1965231. DOI: 10.1155/2020/1965231.

23. Sundberg J, Estrada C, Jenkins C, Ray J, Abramo T. Hypothermia is associated with poor outcome in pediatric trauma patients. Am J Emerg Med 2011;29(9):1019-1022. DOI: 10.1016/j.ajem.2010.06.002. 